\title{
Case Report: A rare presentation and diagnosis of gingival melanoacanthoma caused by teeth whitening strips [version
}

\section{1; peer review: 2 approved]}

\author{
Hamad Albagieh (D1) Ashwag Aloyouny (D2), Shatha Alharthi³
}

${ }^{1}$ Oral Medicine and Diagnostic Science Department, College of Dentistry, King Saud University, Riyadh, Saudi Arabia

${ }^{2}$ Basic Dental Science Department, College of Dentistry, Princess Nourah bint Abdulrahman University, Riyadh, Saudi Arabia

${ }^{3}$ Preventive Dental Science Department, College of Dentistry, Princess Nourah bint Abdulrahman University, Riyadh, Saudi Arabia

\author{
V1 First published: $14 \operatorname{Dec} 2020,9: 1452$ \\ https://doi.org/10.12688/f1000research.27999.1 \\ Latest published: 21 Dec 2020, 9:1452 \\ https://doi.org/10.12688/f1000research.27999.2
}

\section{Abstract}

Background: Oral melanoacanthoma is not common. It occurs mostly on the buccal mucosa. Since it happens suddenly and progresses rapidly, it clinically resembles melanoma. Melanoacanthoma occurs in regions susceptible to trauma. The clinical presentation of the lesion is not enough to diagnose it; therefore, tissue biopsy is necessary to exclude malignancy.

Case report: We report a case of oral melanoacanthoma in a rare mucosal location in a 21-year old female patient. The generalized gingival melanoacanthoma was caused as a result of using teeth whitening strips. This irritating factor increased melanocyte activity in the gingival tissues and labial mucosa.

Discussion: Oral melanoacanthoma is a rarely encountered pigmented lesion in the oral cavity and is especially uncommon in the gingiva. It is a reactive lesion affecting the mucous membranes with no risk of malignant transformation. This case report shows that teeth whitening strips may trigger oral melanoacanthoma in susceptible individuals. Long-term irritation of the oral tissues may increase the number of dendritic melanocytes throughout the epithelium and accordingly increase the brown pigmentation of the oral cavity. Eliminating all possible local sources of irritation and ruling out other causative factors are the standard first steps in the oral melanoacanthoma therapy.

Conclusions: This case shows the importance of including oral melanoacanthoma in the differential diagnosis of diffuse gingival pigmented lesions.

\section{Keywords}

Oral Melanoacanthoma, gingival hyperpigmentation, oral pigmented lesion, teeth whitening strips.

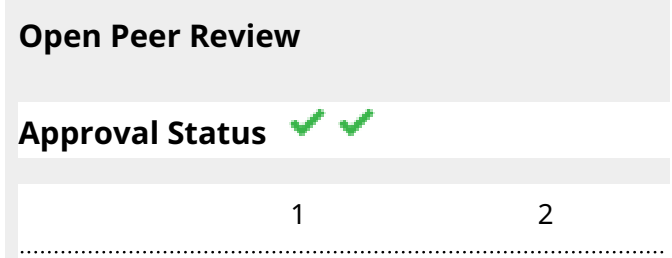

version 2

(revision)

21 Dec 2020

version 1

14 Dec 2020

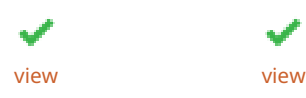

1. Mahnaz Fatahzadeh, Rutgers School of

Dental Medicine, Newark, USA

2. Lujain Homeida (D), Umm Al-Qura

University, Makkah, Saudi Arabia

Any reports and responses or comments on the article can be found at the end of the article. 
Corresponding author: Ashwag Aloyouny (aloyouas-j@hotmail.com)

Author roles: Albagieh H: Supervision, Writing - Original Draft Preparation, Writing - Review \& Editing; Aloyouny A: Data Curation, Resources, Writing - Original Draft Preparation, Writing - Review \& Editing; Alharthi S: Investigation, Supervision, Writing - Original Draft Preparation

Competing interests: No competing interests were disclosed.

Grant information: This research was funded by the Deanship of Scientific Research at Princess Nourah bint Abdulrahman University through the Fast-track Research Funding Program.

Copyright: @ 2020 Albagieh $\mathrm{H}$ et al. This is an open access article distributed under the terms of the Creative Commons Attribution License, which permits unrestricted use, distribution, and reproduction in any medium, provided the original work is properly cited.

How to cite this article: Albagieh $\mathrm{H}$, Aloyouny $\mathrm{A}$ and Alharthi $\mathrm{S}$. Case Report: A rare presentation and diagnosis of gingival melanoacanthoma caused by teeth whitening strips [version 1; peer review: 2 approved] F1000Research 2020, 9:1452

https://doi.org/10.12688/f1000research.27999.1

First published: 14 Dec 2020, 9:1452 https://doi.org/10.12688/f1000research.27999.1 


\section{Introduction}

Oral Melanoacanthoma is a rare, pigmented lesion that usually occurs on the buccal mucosa. The most common site of oral melanoacanthoma is the buccal mucosa $(51.4 \%)$, followed by the palate $(22.2 \%)$, and lips $(15.2 \%)$. The gingiva is least affected by melanoacanthoma $(5.6 \%)^{1}$. A review of the literature identified only a few cases with generalized, diffuse, multiple, upper and lower gingival melanoacanthoma ${ }^{2}$. Clinical differentiation between benign and malignant oral pigmented lesions is very difficult at early stages. Generalized gingival melanoacanthoma is extremely rare, therefore, tissue biopsy is highly recommended to differentiate between melanoacanthoma and melanoma. We present a rare case of melanoacanthoma in the gingivae and the labial mucosae triggered by teeth whitening strips in a 21-year-old female patient. The work is reported in line with the CARE criteria ${ }^{3}$.

\section{Case report}

The patient of this case report was a 21-year-old female, Saudi Arabian college student. She was referred by her dentist in July 2018 to an oral medicine specialist for evaluation of a three-month-history of remarkable intraoral, diffuse hyperpigmentation of the upper and lower gingivae and labial mucosae. She reported that the hyperpigmentation appeared suddenly and had rapidly increased in size. The patient reported using teeth whitening strips for six weeks before the intraoral pigmentation happened. Her past medical history revealed hypothyroidism for three years for which she had been taking $100 \mathrm{mcg} /$ day of levothyroxine sodium. She was not on any other mediation. She was not aware of any relevant family history of extensive brown oral pigmentation. She reported no history of mental health disorders and denied the use of tobacco products. The patient was referred to an endocrinologist to rule out systemic diseases such as Addison's disease. Accordingly, a blood test was carried out and the results were all within normal limits; red blood cell count of $4.99 \times 10^{6} / \mu \mathrm{L}$, platelet count of $259 \times 10^{3} / \mu \mathrm{L}$, hemoglobin count of $13.3 \mathrm{~g} / \mathrm{dL}$, white blood cell count of $8.88 \times 10^{3} / \mu \mathrm{L}$, lymphocytes $33.6 \%$, segmented neutrophil 54.6\%, ferritin $31.11 \mathrm{ng} / \mathrm{mL}$, iron $14.6 \mathrm{umol} / \mathrm{L}$, FT4 $17.67 \mathrm{ng} / \mathrm{dL}$, TSH $0.079 \mathrm{mIU} / \mathrm{L}$, Vitamin D $65 \mathrm{ng} / \mathrm{mL}$ and cortisol $184.9 \mathrm{nmol} / \mathrm{L}$. A physical examination revealed no skin pigmentation and an extraoral examination showed no significant findings. An intraoral examination showed asymptomatic, diffuse, smooth, macular blackish-brown pigmentation with irregular margins on both the upper and lower attached and free gingivae, and upper and lower labial mucosae (Figures 1a-1c).

The clinical presentation and the widespread nature of the lesion were worrisome to the clinician; therefore an incisional biopsy was performed. The goals and expectations of the procedure were discussed with the patient as well as the potential risks for surgical and post-surgical complications such as bleeding, swelling, discomfort, infection and scarring. Written informed consent was obtained from the patient. After applying $1.8 \mathrm{~mL}$ of the anesthetic solution (lidocaine HCL 2\% and epinephrine $1: 100,000)$ via intraoral injection to the gingival area of tooth No. 33 , a $3 \mathrm{~mm}$ section of gingival tissue was removed at the
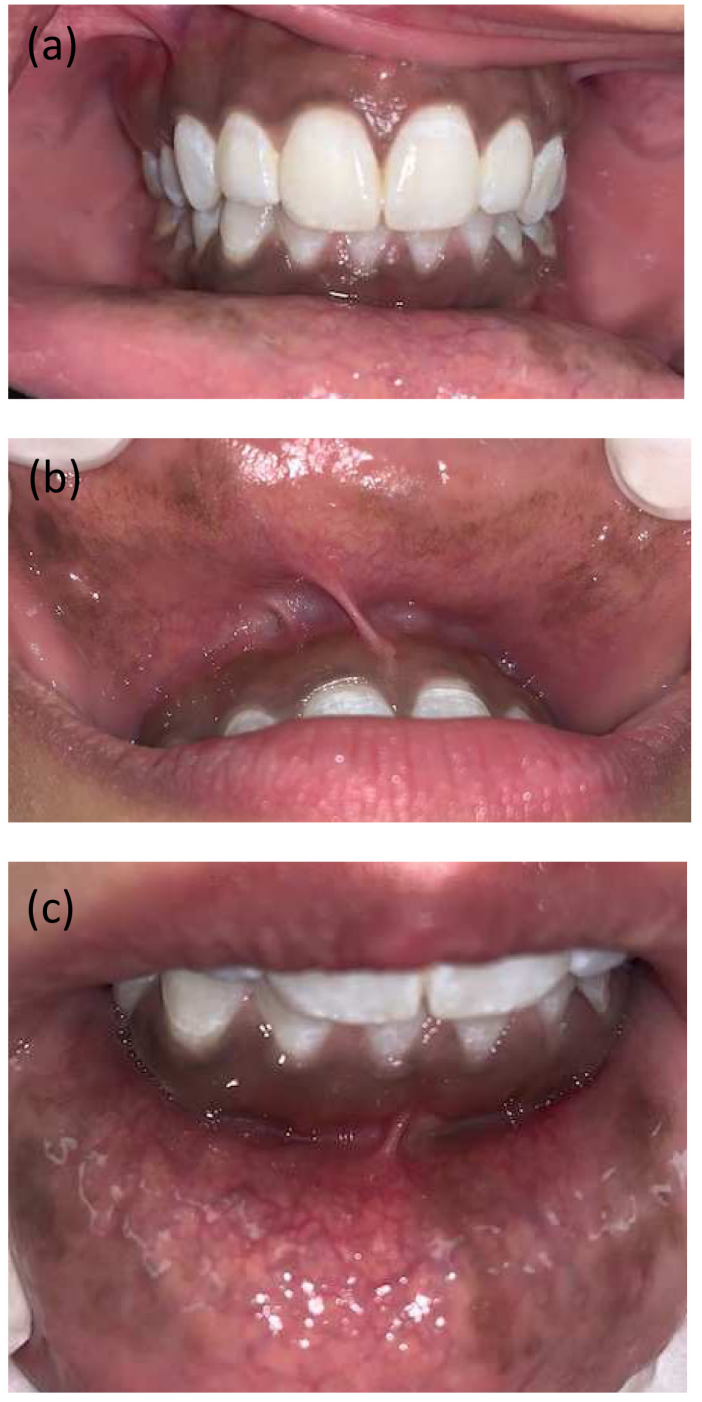

Figure 1. Clinical photographs of oral melanoacanthoma. Macular brown pigmentation with irregular margins involving (a) upper and lower attached and free gingivae; (b) upper labial mucosa; (c) lower labial mucosa.

apical area of tooth No. 33, at the darkest pigmented spot of the lesion and a bit away from the esthetic zone. The incised tissue was blackish-brown in colour and measured $0.3 \times 0.2 \times$ $0.1 \mathrm{~cm}$. The gross specimen was fixed in $10 \%$ neutral buffered formalin and then submitted as one piece in one cassette for histopathology examination. The microscopic analysis of the hematoxylin and eosin (H\&E) stained sections showed a hyperorthokeratinized, hyperplastic, stratified squamous epithelium revealing acanthosis, and long rete ridges. Many benign dendritic melanocytes with pigment-laden dendritic processes were distributed in the epithelium. In addition, melanin pigmentation of basal cell layer was noted with evidence of melanin deposits in the lamina propria (Figure 2). A microphotograph of Melan-A stained tissue shows melanotic hyperplasia in the epithelium (Figure 3). 


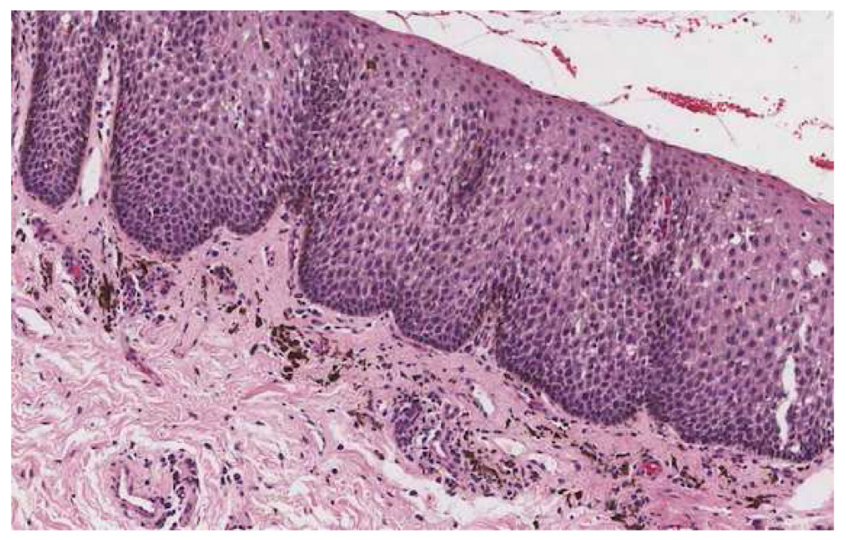

Figure 2. Microphotograph of the stained biopsy tissue. Microphotograph of hematoxylin and eosins stained tissue shows the parakeratinized, hyperplastic, stratified squamous epithelium with acanthosis, and long rete ridges. Many benign dendritic melanocytes with dendritic processes can be seen distributed in the epithelium, as well as melanin deposits in the lamina propria.

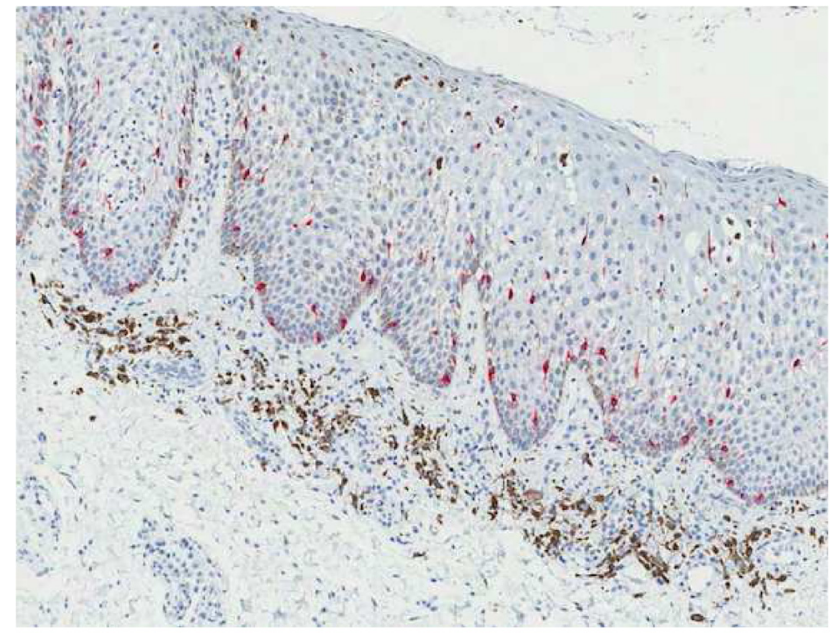

Figure 3. Microphotograph of Melan-A stained biopsy tissue. Microphotograph of Melan-A stained biopsy tissue shows melanotic hyperplasia in the epithelium.

In light of the patient history, clinical presentation, and the histopathology report of the incisional biopsy, the final diagnosis of oral melanoacanthoma was confirmed. The patient was reassured of the benign nature of the lesion and she was advised to stop using the teeth whitening strips. At 8-months follow up, the lesion had gradually faded (Figure 4).

\section{Discussion}

Cutaneous melanoacanthoma was first reported in 1927, yet oral melanoacanthoma was not described until 1978. Melanoacanthoma was named by Mishima and Pinkus in $1960^{5,6}$. It shares some of the alarming characteristic features of malignant

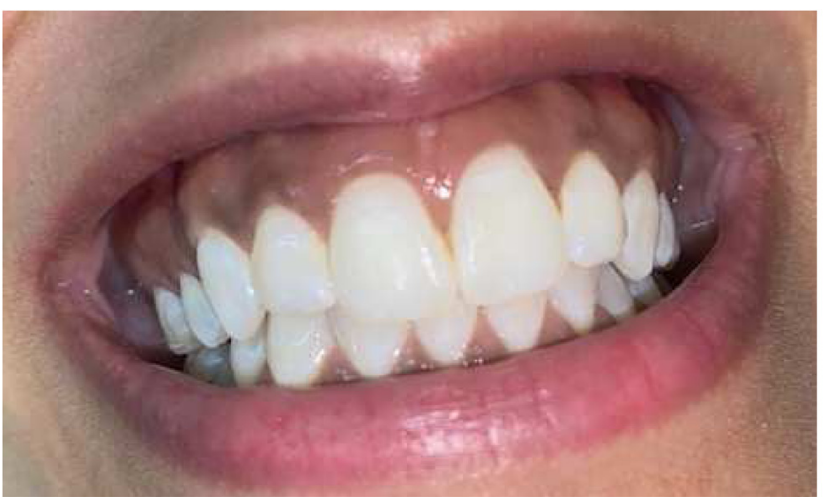

Figure 4. Follow-up clinical photograph. An eight-monthfollow up visit revealed that the brown pigmentation had faded gradually.

melanoma such as sudden appearance and rapid growth rate. It is described as asymptomatic, solitary or multifocal, and diffuse, with ill-defined areas of dark brown to black pigmentation, a flat macule or slightly raised, and is usually greater than $1 \mathrm{~cm}$ in diameter. It usually occurs in teenage to middle-aged women with dark skin pigmentation?

The exact pathophysiology of oral melanoacanthoma is undetermined; however, the clinical manifestations of the lesion is suggestive of a reactive origin, since it occurs mainly in regions liable to trauma ${ }^{8}$. The oral melanoacanthoma, in this reported case, occurred on the soft tissue areas that came in close contact with the teeth whitening strips. After excluding all other potential causes, the author believed that the teeth whitening strips could have participated in the oral pigmented lesion in this patient, resulting in diffused hyperpigmentation. These teeth whitening strips could have been a source of irritation to the tissues as they contain a gel that has active chemical ingredients such as hydrogen peroxide. Prolonged exposure to high concentrations of hydrogen peroxide can damage oral soft tissues ${ }^{9}$.

The differential diagnoses of oral melanoacanthoma includes: melanoma, Addison's disease, McCune-Albright syndrome, Peutz-Jeghers syndrome, physiologic racial pigmentation, post-inflammatory lichen planus, acquired melanocytic nevus, and oral melanotic macules ${ }^{10}$. Gingival pigmentation may also be caused by amalgam material, chewing tobacco (khat), gingival tattoo, graphite implantation, and several hygiene products. Moreover, utilizing different heavy metals and some medically prescribed drugs could participate in the presence of pigmented lesions in the mouth ${ }^{2}$. Fortunately, oral melanoacanthoma has an excellent prognosis; in most of the reported cases, the pigmented lesions start to fade gradually either after removing the causative factor such as dental hygiene products or tobacco products, or following minor trauma such as tissue biopsy or sharp food injury. In the present case, pigmentation gradually disappeared after performing the incisional gingival tissue biopsy of the lesion. Eliminating all possible local sources of 
irritation and ruling out other causative factors are the standard first step in the oral melanoacanthoma therapy.

This case study has many strengths; the clinical examination was done thoroughly, the laboratory result was reviewed carefully, and complete data was collected. After that, a tissue biopsy from the lesion was performed to determine the condition and based on the histopathology report, the causative factor was eliminated. As a result, the lesion regressed gradually.

\section{Conclusion}

Oral melanoacanthomas are rarely encountered pigmented lesions in the oral cavity. They are especially rare in the gingival region. These pigmented lesions should be biopsied and carefully analyzed under the microscope to rule out a diagnosis of a malignant lesion such as melanoma. This case report highlights the important role of dentists to include oral melanoacanthoma in the differential diagnosis of diffuse gingival pigmented lesions.

\section{Patient perspective}

The patients reported that the disappearance of the brown discoloration had a good impact on the esthetic appearance of her smile which allowed her to regain confidence.

\section{Consent}

Written informed consent was obtained from the patient for publication of this case report and accompanying images.

\section{Data availability statement}

All data underlying the results are available as part of the article and no additional source data are required.

\section{Acknowledgements}

This research was funded by the Deanship of Scientific Research at Princess Nourah bint Abdulrahman University through the Fast-track Research Funding Program.
1. Yarom N, Hirshberg A, Buchner A: Solitary and multifocal oral melanoacanthoma. Int J Dermatol. 2007; 46(12): 1232-1236. PubMed Abstract | Publisher Full Text

2. Datta A, Lamba AK, Tandon S, et al.: A Unique Presentation of Gingival Melanoacanthoma: Case Report and Review of Literature. Cureus. 2020; 12(3): e7315.

PubMed Abstract | Publisher Full Text | Free Full Text

3. Agha RA, Borrelli MR, Farwana R, et al: The SCARE 2018 statement: Updating consensus Surgical CAse REport (SCARE) guidelines. Int J Surg. 2018; 60: 132-136. PubMed Abstract | Publisher Full Text

4. Andrews BT, Trask DK: Oral melanoacanthoma: a case report, a review of the literature, and a new treatment option. Ann Otol Rhinol Laryngol. 2005; 114(9): 677-680.

PubMed Abstract | Publisher Full Text

5. Tomich C: Abstract of the 32nd Annual Meeting. Am Acad Oral Pathol Ft Lauderdale, Fla.
6. Mishima $\mathrm{Y}$, Pinkus $\mathrm{H}$ : Benign mixed tumor of melanocytes and malpighian cells. Melanoacanthoma: Its relationship to Bloch's benign non-nevoid melanoepithelioma. Arch Dermatol. 1960; 81(4): 539-50. PubMed Abstract | Publisher Full Text

7. Brooks JK, Sindler AJ, Scheper MA: Oral melanoacanthoma in an adolescent. Pediatr Dermatol. 2010; 27(4): 384-387. PubMed Abstract | Publisher Full Tex

8. Tomich CE, Zunt SL: Melanoacanthosis (melanoacanthoma) of the oral mucosa.J Dermatol Surg Oncol. 1990; 16(3): 231-236. PubMed Abstract | Publisher Full Text

9. Walsh LI: Safety issues relating to the use of hydrogen peroxide in dentistry. Aust Dent J. 2000; 45(4): 257-269; quiz 289. PubMed Abstract | Publisher Full Text

10. Neville BW, Damm DD, Allen CW, et al.: Epithelial Pathology. Oral and Maxillofacial Pathology. 3rd ed. W.B. Saunders, Philadelphia; 2009. 


\section{Open Peer Review}

\section{Current Peer Review Status:}

\section{Version 1}

Reviewer Report 21 December 2020

https://doi.org/10.5256/f1000research.30968.r76102

(C) 2020 Homeida L. This is an open access peer review report distributed under the terms of the Creative Commons Attribution License, which permits unrestricted use, distribution, and reproduction in any medium, provided the original work is properly cited.

\section{Lujain Homeida}

Faculty of Dentistry, Umm Al-Qura University, Makkah, Saudi Arabia

I reviewed the manuscript entitled: " Case Report: A rare presentation and diagnosis of gingival melanoacanthoma caused by teeth whitening strips" and found it of interest to the readers of F1000Research.

In this paper, they reported a case of a rare pigmented mucosal melanoacanthoma with uncommon trigger. The importance of this case arises from its resemblance clinically to malignant melanoma such as sudden appearance and rapid growth rate. However, melanoacnthoma has no risk of malignant transformation. They concluded by emphasizing on considering oral melanoacanthoma in the differential diagnosis of diffuse gingival pigmented lesion.

This case report highlights the importance of investigating cases with oral pigmented lesions through detailed history taking and clinical work up to rule out any potential malignancies. The presented clinical evaluation and management of this case is excellent. I found this paper very relevant to the scope of this journal. The only point I would arise here is that they referred to some relatively old references and I would kindly advise them to use more updated references.

Is the background of the case's history and progression described in sufficient detail? Yes

Are enough details provided of any physical examination and diagnostic tests, treatment given and outcomes?

Yes

Is sufficient discussion included of the importance of the findings and their relevance to future understanding of disease processes, diagnosis or treatment?

Yes

Is the case presented with sufficient detail to be useful for other practitioners? 
Yes

Competing Interests: No competing interests were disclosed.

Reviewer Expertise: Oral medicine/ TMDs/Medcially compromised patients.

I confirm that I have read this submission and believe that I have an appropriate level of expertise to confirm that it is of an acceptable scientific standard.

Reviewer Report 15 December 2020

https://doi.org/10.5256/f1000research.30968.r76096

(C) 2020 Fatahzadeh M. This is an open access peer review report distributed under the terms of the Creative Commons Attribution License, which permits unrestricted use, distribution, and reproduction in any medium, provided the original work is properly cited.

\section{Mahnaz Fatahzadeh}

Department of Diagnostic Sciences, Rutgers School of Dental Medicine, Newark, USA

The case is well-documented and the article is well-written. Perhaps, a reviewer in that field may offer additional insights regarding the photomicrographs.

I have made a few minor suggestions to improve the article as follows:

Title: It may be more appropriate to change it to "A rare presentation of gingival melanoacanthoma caused by teeth whitening strips: A Case Report".

Abstract, case report paragraph: Please combine 1st and 2nd sentence as follows" ..... female patient in whom generalized gingival melanaoacanthoma was related to the use of teeth whitening strips."

Abstract, discussion paragraph, last sentence: change to "..... first step in treatment of oral melanoacanthoma."

Page 3, case report, 1st paragraph: It is appropriate to include if patient reported bronzing of her skin or not.

Page 3, case report, 1st paragraph: If available, please include the result of typical tests for Addison's disease (serum Na, K, cortisol, ACTH and their normal ranges).

Page 3, case report, second paragraph: I agree that biopsy was warranted to determine the nature of diffuse oral pigmentation in this case. However; melanoma would be a less likely concern in this case. Oral melanoma is rare and presentation of gingival melanoma in both jaws is even more rare.

Page 4, discussion, second paragraph: correct the spelling for the word "diffuse". 
Page 4, discussion, third paragraph: Did the mandibular gingival pigmentation also resolve over time? If so, it is more likely to be due to discontinuation of whitening strips rather than biopsy performed in maxilla.

Is the background of the case's history and progression described in sufficient detail? Yes

Are enough details provided of any physical examination and diagnostic tests, treatment given and outcomes?

Yes

Is sufficient discussion included of the importance of the findings and their relevance to future understanding of disease processes, diagnosis or treatment?

Yes

Is the case presented with sufficient detail to be useful for other practitioners? Yes

Competing Interests: No competing interests were disclosed.

Reviewer Expertise: Oral medicine

I confirm that I have read this submission and believe that I have an appropriate level of expertise to confirm that it is of an acceptable scientific standard.

The benefits of publishing with F1000Research:

- Your article is published within days, with no editorial bias

- You can publish traditional articles, null/negative results, case reports, data notes and more

- The peer review process is transparent and collaborative

- Your article is indexed in PubMed after passing peer review

- Dedicated customer support at every stage

For pre-submission enquiries, contact research@f1000.com 